\title{
Covid-19: Pandemonium in our time
}

\author{
Robert Bergquist ${ }^{1}$ and Laura Rinaldi ${ }^{2}$ \\ ${ }^{1}$ Geospatial Health, Ingerod, Brastad, Sweden; ${ }^{2}$ Laboratory of Parasitology and Parasitic Diseases, \\ Department of Veterinary Medicine and Animal Production, University of Naples Federico II, Naples, Italy \\ (WHO Collaborating Centre ITA-116)
}

\section{Introduction}

While pandemonium has come to mean wild and noisy disorder, the reference here is to John Milton's epic poem Paradise Lost and the upheaval following Lucifer's banishment from Heaven and his construction of Pandcemonium as his hub. Today's avalanche of conflicting news on how to deal with the coronavirus disease 2019 (Covid-19) not only brings this to mind, but also the Trinity nuclear bomb test with Enrico Fermi estimating its strength by releasing small pieces of paper into the air and measuring their displacement by the shock wave. Fermi's result, in fact not far from the true value, emphasised his ability to make good approximations with few or no actual data. The current wave of Covid-19 presents just this kind of situation as it engulfs the world from Ground Zero in Wuhan, China. Much information is indeed missing, but datasets that might lead to useful ideas on how to handle this pandemic are steadily accumulating.

\section{More easily transmissible and more deadly than influenza}

The coronaviruses not only closed the gap between animal and human infections, but also made inter-human transmission possible. It is now believed that Severe Acute Respiratory Syndrome (SARS) was originally transmitted from civet cats or bats (Shi and $\mathrm{Zu}, 2008$ ) and Middle East Respiratory Syndrome (MERS) from camels to humans (WHO, 2019), while the original source of SARS-CoV-2, the virus causing Covid-19, still remains unknown. The SARS and MERS viruses have only been known since the last

Correspondence: Robert Bergquist, Ingerod, Brastad, Sweden.

E-mail: editor@geospatialhealth.net

Received for publication: 30 March 2020

Accepted for publication: 30 March 2020

${ }^{\circ}$ Copyright: the Author(s),

Licensee PAGEPress, Italy

Geospatial Health 2020; 15:880

doi:10.4081/gh.2020.880

This article is distributed under the terms of the Creative Commons Attribution Noncommercial License (CC BY-NC 4.0) which permits any noncommercial use, distribution, and reproduction in any medium, provided the original author(s) and source are credited. two decades but were stopped in their tracks long before reaching the pandemic level. SARS-CoV-2, however, once set free from its animal containment is giving rise to desperate countermeasures. Nonetheless, within a few months since its emergence in central China in late November 2019, this virus has reached almost all of the inhabited world. It is thus obvious that it cannot be stopped, and we must now find ways to live with it just as we have learnt to live with previous pandemics; the problem this time though is that Covid-19 is creating something more like the Black Death than a flu epidemic.

Covid-19's predilection for the lungs makes it both contagious and life-threatening. Its reproduction ratio $\left(\mathrm{R}_{0}\right)$, defined as the expected number of cases generated by a single infected case in a susceptible population (Fraser et al., 2009), varies between 2.4 and 2.7 (Liu et al., 2020), which is high compared to that of influenza (1.3-1.8) (Biggerstaff et al., 2014). The infected proportion of the world population in previous viral pandemics has fallen since the Russian flu 1889-1890, as have mortality rates (Valleron et al., 2010; WHO, 2011), but the higher $\mathrm{R}_{0}$ of Covid-19 might reverse that trend. However, as noted by Viceconte and Petrosillo (2020), epidemiological trends and control capabilities cannot rely on $\mathrm{R}_{0}$ only, but must also take into account a variety of other variables, such as: the number of initial cases; the delay from onset to isolation; contact tracking; reproduction in the presence of control measures; and the proportion of subclinical infections. In addition, climatic factors and people keeping sufficient distance between each other can change the $\mathrm{R}_{0}$ considerably, e.g., both gatherings of people in close quarters and the cold and dry winter months in the northern hemisphere are known to favour transmission of respiratory viruses in general (Lowen et al., 2007; Li WT et al., 2020).

\section{Number of infections and number of deaths}

The L. Spallanzani National Institute for Infectious Diseases, in Rome was the first Italian hospital to admit and manage patients affected by Covid-19. Even though the first patients presented with limited clinical evidence, expert recommendations for the management of these patients were developed quickly and have greatly aided in the care of the large numbers of patients in Italy (Nicastri et al., 2020). Even if many of the factors involved in the Covid-19 pandemic are still poorly understood, they are now largely recognized. Although some deaths attributed to Covid-19 occur outside the health care system and some are misdiagnosed, the mortality numbers are quite reliable, something which cannot be said about the true number of infections, sine qua non we are groping in the dark regarding the distribution and ongoing spread of this disease. The risk it poses depends on knowing the true numbers of those actually infected at any given time. 
For example, the Case Fatality Rate (CFR), defined as the ratio between the number of deaths and the number of confirmed cases, does not provide a firm probability of disease-related deaths since CFR also depends on the kind of treatment received and on the patients' ability to recover. Thus, this measure reflects only the severity of a disease in a particular context, e.g., in young as opposed to old people, as seen in Figure 1. Since the strong advance of Covid-19 has led to a focus on mortality and outward signs of disease rather than on large-scale diagnostic testing, one would expect the CFR to rise over time and this is exactly what we are seeing. CFR was $2.2 \%$ on 31 January 2020 , a month later the World Health Organization (WHO) put forward the figure 3.4\% (WHO, 2020a) and it stands now (30 March) at 4.6\%. The Infection Fatality Rate (IFR), i.e. the ratio between the number of deaths and the total number of those infected, is a better mortality metric, but this value cannot be calculated since large numbers of people have not been tested due to negligible clinical signs (as well as the current lack of diagnostic assays). Thus, those infected but with only minor or no symptoms can be many times larger than those with overt signs of infection, which tells us that the risk for developing life-threatening pathology could be much lower than what is indicated by the CFR. Therefore, production and application of diagnostics are increasingly important.

Recent information from the Italian Ministry of Health (2020) and an investigation covering more than 72,000 Chinese patients diagnosed with Covid-19 (Wu and McGoogan, 2020) both show the CFR to be high only for people older than 50 years (Figure 1). The difference between the countries is statistically significant for the 70-79 age group, which is reflected by the unusually high mortality levels in northern Italy. Another recent report by the Italian Ministry of Health (2020) shows that a large number of the fatalities $(48.5 \%)$ were seen in people simultaneously afflicted by three or more underlying diseases. The median age at death was 79.5 years with only 17 persons $(0.8 \%)$ less than 50 years old and none below 30 . These results are mirrored by an equally recent study from Wuhan, China, where the authors also point to an array of laboratory data that could help identify patients with poor prognosis at an early stage (Zhou et al., 2020). Although this casts some

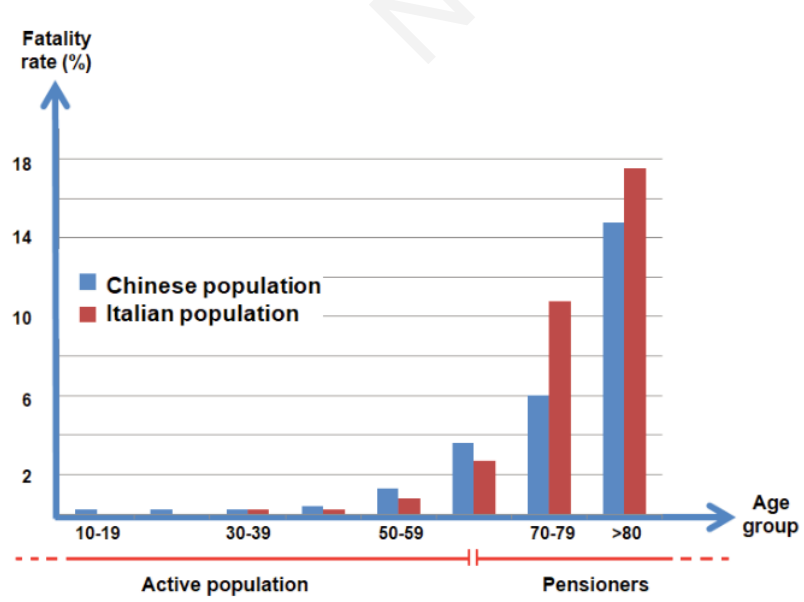

Figure 1. Fatality risk of Covid-19 according to age group in China and Italy. light over the high death toll in Italy, one still wonders why mortality varies so much between countries.

According to a graph depicting the worldwide growth of Covid-19 published by Cohen and Cupferschmidt in Science (2020), the disease in most countries develops along a common pattern characterized by a closely aligned, logarithmic upward trend during the first 15 days after that the first 100 cases have been identified, but there are conspicuous differences. The graph clearly shows that the cumulative numbers of infection in China and South Korea are plateauing, the former 30 days and the latter 20 days after the first 100 cases, while the numbers in Japan and Singapore have continued to increase but at a much slower rate, as also seen in other neighboring countries (https://www. worldometers.info/coronavirus/). In spite of the fact that Japan, South Korea, Hong Kong, Singapore and Taiwan all identified their first cases very early (mid January), only the latter three acted rapidly. As noted by Laignee Barron, reporting from Hong Kong in Time Magazine (2020), Hong Kong, Singapore and Taiwan implemented travel restrictions on passengers coming from China already from 1 February 2020 and immediately instituted effective responses that had less to do with an authoritarian streak than with transparency, comprehensive testing and quick quarantining of suspected cases. However, they also applied electronic surveillance - more about that later.

Lock-down seems to be the universally most used approach but national variations of this strategy are being attempted. For example, The Netherlands has chosen a balance between building up a so-called 'herd immunity' by allowing exposure to infection in low-risk groups, such as children or young adults without any underlying diseases, while at the same time maintaining containment to keep the demand for hospital beds below maximum capacity. The U.K. government was at first positive to promoting immunity along the same lines but then changed tack and has now gone for a strong lock-down policy. The mitigation strategy used in Sweden, on the other hand, has so far been relaxed with the government issuing recommendations rather than strict rules, and the country has kept its primary and secondary schools open. In addition to assumed immunity promotion, this approach has allowed essential services to continue uninterrupted since many core-staff parents with young children now do not have to stay at home. Summarizing the information given above, it is evident that that all roads do not lead to Rome. For example, Japan and Sweden have so far done well without strong countermeasures, but the herdimmunity approach in The Netherlands has yet to produce the expected result. Italy stands out as the country with the highest number of both confirmed cases and fatalities in Europe, while Germany has a low number of fatalities in spite of a comparatively high number of confirmed cases.

The examples given in the preceding paragraph are examples from the list of countries with the highest numbers of infection (https://www.worldometers.info/coronavirus/). The results are often contradictory which may be due to the necessity of using CFR in the absence of IFR. Widespread testing, including antibody detection, would put the premonition protective immunity on a stronger footing. What is clear is the strong progress with respect to mitigation of transmission in the Far East. However, what is not so clear is the role played by electronic tracking practiced by many countries in this part of the world.

A growing number of countries and territories China, South Korea, Hong Kong, Singapore and Taiwan, have avoided complete, national closures but still succeeded in strongly mitigating 
the spread of SARS-CoV-2. However, to achieve this, they have resorted to approaches that test to the limit citizens' rights to privacy, e.g., the use of smartphone technology and other surveillance systems to trace recent movements of Covid-19 patients and determine how many people are obeying government lockdown orders. South Korea started early on with massive test sessions linked to systematic updates through smartphone messaging advising people to avoid certain areas (Barbieri and Darnis, 2020). Although this kind of surveillance threatens the precarious balance between public safety and personal privacy, authorities are understandably eager to employ whatever it takes to stop the virus. Not surprisingly, this has raised concerns, particularly in Europe where the European Union (EU) has developed and adopted laws addressing collection and transfer of personal data - the General Data Protection Regulation (GDPR) governs data protection and privacy in the European Economic Area (European Commission, 2020). This notwithstanding, the Italian Ministry of Innovation Technology and Digitalization has launched a call as of March 24 for technologies and solutions for continuous tracking, alerting and controlling the level of exposure to Covid-19, which includes hardware and software utilizing smartphone applications (apps) based on Geographical Information Systems (GIS), as well as drones and systems based on artificial intelligence; Israel has also shown interest in this direction (Barbieri and Darnis, 2020).

\section{Geospatial techniques to the rescue}

Figure 2 shows the worldwide development of Covid-19 from 10 January to the end of March. The diagram includes: i) active cases in China, i.e. the cumulative number of all cases reported so far minus the patients who have either recovered or died; ii) the corresponding worldwide number of active cases; and iii) all (in the world) who have recovered after infection. The cumulative

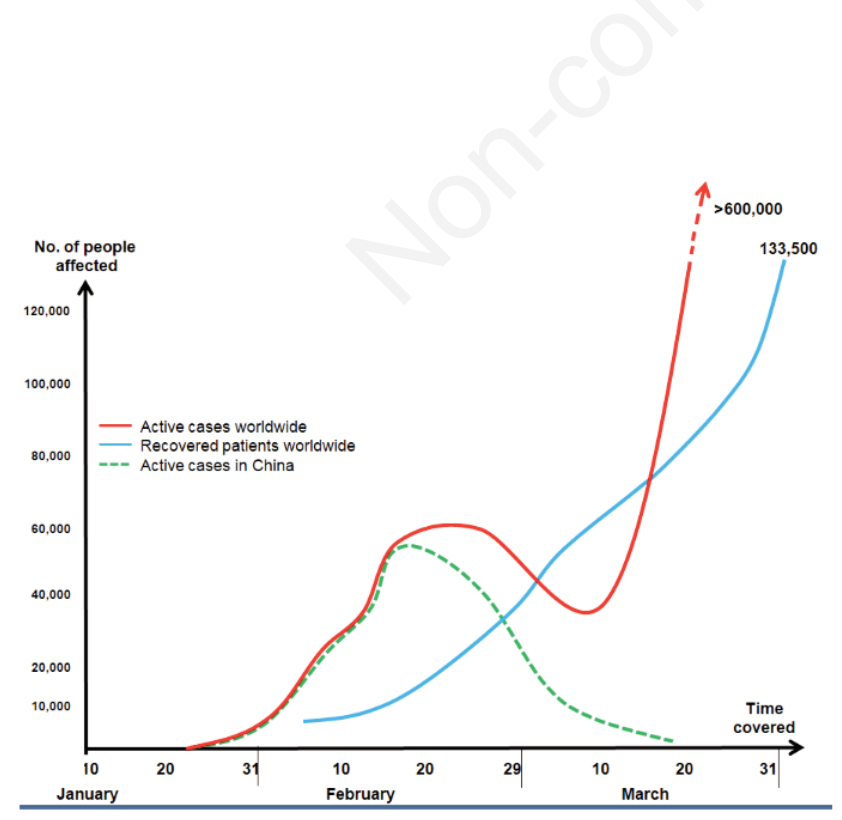

Based on information as of 30 March, 2020

Figure 2. Covid-19 development, based on information as of 30 March, 2020. number of infected persons in China has settled just above 80,000 cases, almost all of them now recovered, with only a sprinkling of new cases registered daily, indicating that the disease has more or less run its course and that so-called herd immunity may have developed. The relentless worldwide increase in the number of active cases (the red curve) since early March 2020 reflects that the epicentre has moved from China to Europe, USA and other countries. Thus, they now comprise the curve from this point, while its first part (up to the beginning of March) shows the situation in China only. Suggestive signs by the end of March (the blue curve) can be the start of an accelerating number of patients recovering, and this provides a glimmer of hope that immunity may be taking hold.

Thanks to off-the-shelf software equipped with spatial statistics packages, follow-up of epidemiological results can be visualized and presented to decision-makers in ways enabling rapid response. This issue of Geospatial Health features two interesting papers from China using such approaches, one dealing with the role of climate with respect to virus transmission ( $\mathrm{Li}$ WT et al., 2020), and the other covering the early phase of the ongoing Covid-19 pandemic (Li H et al., 2020). Both provide information useful for the planning of countermeasures against virus epidemics.

\section{New scientific findings}

With young people less affected, and therefore often unaware that they constitute a risk for older people, containment efforts face a major problem, especially as the duration of the viral shedding of SARS-CoV-2 can vary between 8 and 37 days (Wu and McGoogan, 2020). Even if Zhou et al. (2020) give a somewhat shorter time, this information casts into doubt the 14-day quarantine stipulation. At the same time, the results of a pilot trial treating infected patients with a daily dose of $600 \mathrm{mg}$ of hydroxychloroquine indicate that a reduction of viral shedding down to 6 days is achievable (Gautret et al., 2020). If this result is confirmed in larger trials, quarantine times could be significantly reduced, improving the social perspective of this pandemic. Another novel hypothesis from Italy (Tilocca et al., 2020) suggests that close contact with domestic animals, such as dogs and bovines that are often infected by different but taxonomically related coronaviruses, could possibly shield humans against the SARS-CoV-2 due to the high homology between the spike protein epitopes of all coronaviruses. However, the research team in question also theorizes that this similarity could play a more sinister role during rapid, recurrent virus exposures triggering an Antibody-Dependent Enhancement (ADE) reaction associated with a severe clinical picture. Indeed, this could be the explanation for the rapidly deteriorating condition experienced by many doctors and nurses repeatedly exposed to SARS-CoV-2 in high concentrations.

Multiple efforts are under way to develop vaccines to prevent Covid-19 infection. Although none are yet available, much progress is being made with some 40 candidates presently in development (WHO, 2020b). However, even once efficacy and safety have been demonstrated, at least a year would be needed for scaling up production of the large amounts needed. A conservative estimate is therefore that no vaccine will be ready for use until mid-2021. Although the road from first observation to common practise is long and winding, all the advances mentioned above provide hope that Covid-19 can be overcome. 


\section{Conclusions}

The data collected so far permit some preliminary predictions. China is currently emerging from 2 months of high-level containment that is now starting to ease. This development, together with stalling numbers of new confirmed cases in neighbouring countries inspire confidence. On the other hand, the current sprinkle of new cases is an indication that we may have to live with this new viral infection for the foreseeable future. It could thus perhaps become something similar to measles, mumps, pertussis, polio and others, which cannot be controlled without vaccines.

Despite containment efforts in Europe and the U.S., the numbers of Covid-19 are still climbing suggesting a longer period of time before the pandemic is over. Probable outcomes are more difficult to assess although the low CFR for people below pension age, shown in both China and Italy, is a positive sign. However, given the high median age of most countries in the EU and its generally dense habitation, Europe will probably bear the major brunt of hospital cases.

More countries have recently entered the phase of rapid growth of the infection, especially the U.S. where the unclear relationship between federal and state authorities is a worry as management of the crisis without a clear line of command threatens to result in shortages of diagnostics, hospital beds and equipment. The problems with respect to Covid-19 in the southern hemisphere are too early to predict, suffice it say for now that the warmer climate there should be less favourable for transmission.

The worldwide scarcity of direct diagnostic testing kits makes it difficult to know where all hotspots are. In addition, assays for the detection of specific antibodies against SARS-CoV-2 should be developed and deployed without delay: without this kind of test it is impossible to know whether or not patients who have recovered have protective antibodies and, if so, for how long time. Once this kind of information becomes available, GIS software and spatial statistics packages can visualize the data and support rapid decision-making.

Taken together, the factors mentioned above not only make Covid-19 difficult to prevent but also enable it to persist until large numbers of people have either died or recovered. National economies, let alone the whole world's financial health, are as much victims of the Covid-19 pandemic as are the populations affected clinically. If the draconian measures instituted all over the industrialized world continue for much longer, a broad-based collapse could be difficult to avoid which, among all other negative outcomes, would also lead to reduced medical support. At this point in time, the best way forward would probably be to focus on reducing the risk for elderly populations insofar as is possible, using available data on the numbers of people belonging to the various risk groups to estimate the need for hospital beds, supplies and ventilators, and at the same time assessing the true distribution of the infection through large-scale direct testing and serology to identify hotspots and determine if there is such a thing as long-term immunity.

\section{References}

Barbieri C, Darnis JP, 2020. Technology: An Exit Strategy for COVID-19? Commentaries Istituto Affari Internazionali, Commentaries, March 2020, pp 1-4. Available from:
Barron L, 2020. What we can learn from Singapore, Taiwan and Hong Kong about handling Coronavirus. Time, March 13. Available from: https://time.com/5802293/coronavirus-covid 19-singapore-hong-kong-taiwan/

Biggerstaff M, Cauchemez S, Reed C, Gambhir M, Finelli L, 2014. Estimates of the reproduction number for seasonal, pandemic, and zoonotic influenza: a systematic review of the literature. BMC Infect Dis 14:480. doi:10.1186/1471-2334-14-480.

Cohen J, Kupferschmidt K, 2020. Countries test tactics in 'war' against COVID-19. Science 367:1287-8. doi:10.1126/science .367.6484.1287.

European Commission, 2020. Communication from the commission to the European parliament, the council, the European economic and social committee and the committee of the regions. A European strategy for data. COM 2020;66. Available from: https://eur-lex.europa.eu/legal-content/EN/ TXT/?uri=CELEX: 52020DC0066. Accessed on 29 March 2020.

Fraser C, Donnelly CA, Cauchemez S, Hanage WP, Van Kerkhove MD, Hollingsworth TD, Griffin J, Baggaley RF, Jenkins HE, Lyons EJ, Jombart T, Hinsley WR, Grassly NC, Balloux F, Ghani AC, Ferguson NM, Rambaut A, Pybus OG, LopezGatell H, Alpuche-Aranda CM, Chapela IB, Zavala EP, Guevara DM, Checchi F, Garcia E, Hugonnet S, Roth C, 2009. Pandemic potential of a strain of influenza A (H1N1): early findings. Science 324:1557-61. doi:10.1126/science. 1176062.

Gautret P, Lagier JC, Parola P, Hoang VT, Meddeb L, Mailhe M, Doudier B, Courjon J, Giordanengo V, Vieira VE, Dupont HT, Honoré S, Colson P, Chabrière E, La Scola B, Rolain JM, Brouqui P, Raoult D, 2020. Hydroxychloroquine and azithromycin as a treatment of COVID-19: results of an openlabel non-randomized clinical trial. Int J Antimicrob Agents. doi:10.1016/j.ijantimicag.2020.105949.

Li H, Li H, Ding ZX, Hu ZB, Chen F, Wang K, Peng ZH, Shen HB, 2020. Spatial statistical analysis of Coronavirus Disease 2019 (Covid-19) in China. Geospat Health, in press.

Li WT, Feng RH, Li T, Du YB, Zhou N, Hong XQ, Yi SH, Zha WT, Lv Y, 2020. Spatio-temporal analysis and visualization of scarlet fever in mainland China from 2004 to 2017. Geospat Health, in press.

Liu Y, Gayle AA, Wilder-Smith A, Rocklöv J, 2020. The reproductive number of Covid-19 is higher compared to SARS coronavirus. J Travel Med 27. doi: 10.1093/jtm/taaa021.

Lowen AC, Samira M, John S, Peter P, 2007. Influenza virus transmission is dependent on relative humidity and temperature. PLoS Pathog 3:1470-6. doi:https://doi.org/10.1371/journal. ppat.0030151

Nicastri E, Petrosillo N, Bartoli TA, Lepore L, Mondi A, Palmieri F, D’Offizi G, Marchioni L, Murachelli S, Ippolito G, Antinori A, 2020. National Institute for the Infectious Diseases "L. Spallanzani”, IRCCS. Recommendations for COVID-19 clinical management. Infect Dis Rep 12:8453. doi: 10.4081/idr. 2020.8543.

National Ministry of health, Italy, 2020. Available from: https:/www.epicentro.iss.it/coronavirus/bollettino/Covid-19infografica_eng.pdf. Accessed on 20 March 2020.

Shi Z, Hu, 2008. A review of studies on animal reservoirs of the SARS coronavirus. Virus Res 133:74-87.

Tilocca B, Soggiu A, Musella V, Britti D, Sanguinetti M, Urbani A, Roncada P, 2020. Molecular basis of COVID-19 relationships 
in different species: a one health perspective. Microbes Infect, Epub 2020 March 17. doi:10.1016/j.micinf.2020.03.002.

Valleron AJ, Cori A, Valtat S, Meurisse S, Carrat F, Boëlle PY, 2010. Transmissibility and geographic spread of the 1889 influenza pandemic. Proc Natl Acad Sci USA. 107:8778-81. doi:10.1073/pnas.1000886107.

WHO, 2011. Implementation of the International Health Regulations (2005). Report of the Review Committee on the Functioning of the International Health Regulations (2005) in relation to Pandemic (H1N1) 2009. Sixty-fourth World Health Assembly 2011 (provisional agenda item 13.2). Available from: https://web.archive.org/web/20150514145306/http:// apps.who.int/gb/ebwha/pdf_files/WHA64/A64_10-en.pdf. Accessed 10 March 2020.

WHO, 2019. Middle East respiratory syndrome coronavirus (MERS-Cov). MERS Monthly Summary, November 2019. Available from: https://www.who.int/emergencies/merscov/en/. Accessed 20 March 2020.

WHOa, 2020. WHO Director-General's opening remarks at the media briefing on Covid-19 3 March. Availble from: https:/www.worl- dometers.info/coronavirus/coronavirus-death-rate/. Accessed 20 March 2020.

WHO, 2020b. Draft landscape of Covid-19 candidate vaccines 20 March 2020. Available from: https:/www.who. int/blueprint/ priority-diseases/key-action/novel-coronaviruslandscape-ncov.pdf. Accessed 20 March 2020.

Wu Z, McGoogan JM, 2020. Characteristics of and important lessons from the coronavirus disease 2019 (Covid-19) outbreak in China. Summary of a report of 72314 cases from the Chinese Center for Disease Control and Prevention. JAMA, Epub 2020 February 24. doi:10.1001/jama.2020.2648.

Viceconte G, Petrosillo N, 2020. COVID-19 R0: Magic number or conundrum? Infect Dis Rep 1:8516. doi:10.4081/idr.2020. 8516.

Zhou F, Yu T, Du R, Fan G, Liu Y, Liu Z, Xiang J, Wang Y, Song B, Gu X, Guan L, Wei Y, Li H, Wu X, Xu J, Tu S, Zhang Y, Chen H, Cao B, 2020. Clinical course and risk factors for mortality of adult in-patients with Covid-19 in Wuhan, China: a retrospective cohort study. Lancet 395:1054-63 doi: https://doi. org/10.1016/S0140-6736(20)30566-3. 